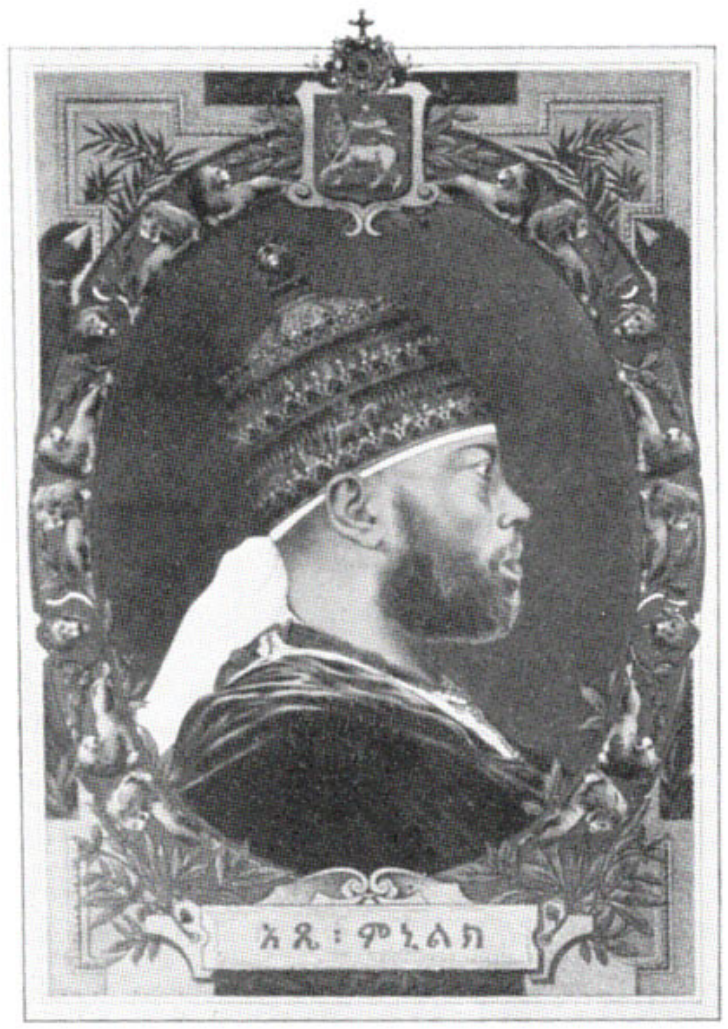




\section{In Abessinien}






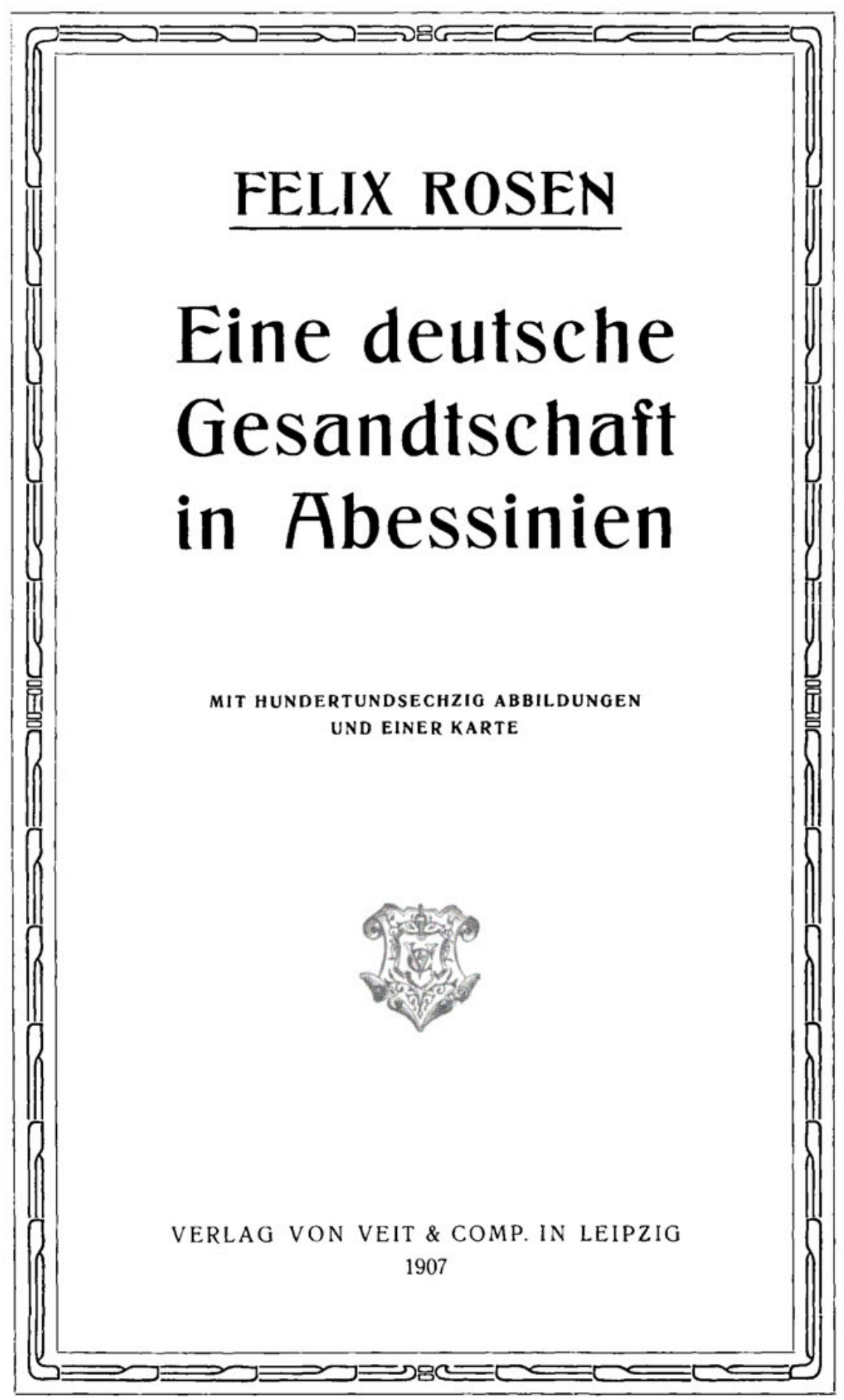


Druck von Fischer \& Wittig in Leipzig 